\title{
La imagen del "indio" en los debates de las Cortes de Cádiz (1810-1812)
}

\section{The Idea of the American Indian in the Debates of the Cadiz Cortes (1810-1812)}

\author{
Francisco Núñez \\ Universidad de Lima
}

\section{RESUIMEN}

El presente artículo trata de identificar, dentro de los debates políticos desarrollados en las sesiones de las Cortes españolas (1810-1812), la imagen construida 0 imaginada de los indígenas americanos. Es la crisis de la monarquía española la que inaugura gran parte de los referentes conceptuales que utilizarán las posteriores repúblicas americanas para establecer sus principios políticos. La ciudadanía será una de las más importantes discusiones políticas en las que se verán involucradas gran parte de las nuevas naciones independientes, sin embargo, toma un matiz particular en aquellas regiones donde la población posee características diferenciadas, lo que generará una complejidad mayor. Esos elementos característicos de aquellas regiones estarán presentes en estas discusiones de las Cortes, y es, en ese contexto, donde nos atrevemos a presentar la forma cómo eran vistas las poblaciones indígenas de América y, en particular, del Perú. Encontramos elementos que tendrán un devenir similar en las décadas posteriores, en donde la modernidad aún reposa sobre ideas que limitan la inclusión indígena.

\section{Palabras clave:}

Ciudadanía / Indígenas / Otredad / Inclusión / Formación de las repúblicas americanas

\begin{abstract}
The present article tries to identify, within the political debates developed in the sessions of the Spanish Cortes (1810-1812), the imagined or constructed image of the American Indians. It is the crisis of the Spanish Monarchy that brings along much of the conceptual references that the later American republics will use to establish their political principles. Citizenship will be one of the most important political discussions in which a large part of the new independent nations will be involved, but it takes a particular note in those regions where the population has different characteristics that will generate a greater complexity. Those particular elements will be present in the debates Cortes. In this context, we dare to present the way in which the indigenous populations of America and in particular of Peru were seen. We find elements that will have a similar pattern in later decades where modernity still rests on ideas that limit indigenous inclusion.
\end{abstract}

\section{Keywords:}

Citizenship / Indigenous / Equality / Political Participation / America / Cadiz Cortes
$\mathrm{E}$ 24 de setiembre de 1810 se instalan en la Isla de León (Cádiz) las Cortes Generales españolas, en pleno proceso de invasión de las tropas napoleónicas a la península. A partir de ese momento se empezará a reconocer este proceso como el inicio de la revolución liberal española. Las modificaciones al orden monárquico que se empiezan a efectuar a partir de la instalación de estas Cortes tomarán la forma de revolución y, a decir de muchos, serán el inicio de la modernidad política para España. América no era ajena a este proceso. Como parte integrante de la Monarquía estaba sujeta a enfrentar estos procesos (la invasión francesa a la península y la convocatoria a Cortes) de manera directa, tanto que, a pesar de los matices y las diferencias políticas y regionales, de una u otra manera, los diferentes territorios americanos se encontraron expectantes y participativos alrededor de estos fenómenos.

El mismo 24 de setiembre, en la sesión inaugural, los diputados americanos protestaron por la desigual representación de América frente a España. A razón de este reclamo, el 15 de octubre de 1810 las Cortes establecen uno de los decretos más importantes antes de promulgarse la Constitución: 
Las cortes generales y extraordinarias confirman y sancionan el inconsuso concepto de que los dominios españoles en ambos hemisferios forman una sola y misma monarquía, una misma y sola nación, y una sola familia, y que por lo mismo los naturales que sean originarios de dichos dominios europeos ó ultramarinos son iguales en derechos á los de esta península, quedando á cargo de las Córtes tratar con oportunidad, y con un particular interés de todo cuanto pueda contribuir á la felicidad de los de ultramar, como también sobre el número y forma que deba tener para lo sucesivo la representación nacional en ambos hemisferios.

Aparece, por primera vez, un escenario propicio para empezar a discutir los criterios y nociones acerca de la igualdad. De este decreto se buscará, por parte de los americanos, lograr y alcanzar mayores niveles de representación a través de los mecanismos propios de la representación y la participación política en clave de modernidad, esto es, los procesos electorales. Por lo tanto, la prédica de los americanos y de los liberales españoles estará en el señalamiento y en la búsqueda de esta igualdad. Ahora bien, los decretos y las leyes posteriores a esta no tendrán mucho impacto en el reconocimiento de la igualdad, en tanto derecho natural; lo que sí encontrará mucha controversia es en el reconocimiento a la igualdad política (Fernández Sebastián y Fuentes, 2002, p. 362). Lo interesante de los debates de las Cortes es encontrar cómo los discursos políticos tienen que replantearse a partir de la resemantización de algunos conceptos, cómo se reinterpretan y cómo luchan con nociones del Antiguo Régimen. Es en ese terreno que encontramos una vitalidad descollante en las Cortes de Cádiz. En efecto, las transformaciones simbólicas, los valores políticos o los nuevos escenarios que plantearon los decretos de las Cortes, como la ciudadanía, la opinión pública ampliada, a partir del decreto de libertad de imprenta, los procesos electorales, entre otros, fueron trascendentales. De ahí que, ahora, y a partir de los estudios de la cultura polí- tica, inaugurados por François-Guerra, Antonio Annino y Jaime E. Rodríguez, se le ha dado una impronta particular a las Cortes de Cádiz como el escenario inaugural de los procesos de independencia hispanoamericana, los que hoy han dado fruto a una serie de estudios, entre cuyos autores, en lo que respecta al caso peruano, Víctor Peralta y Cristóbal Aljovín son los más representativos.

Los debates de las Cortes sobre la cuestión de la igualdad de la representación nos van a llevar a una serie de presupuestos conceptuales sobre los que se discute la misma. El 16 de diciembre de 1810, el primero en levantar la voz para que se discuta esta igualdad (reconocida en el decreto del 15 de octubre) fue Dionisio Inca Yupanqui, diputado suplente por el Perú. El Diario de Discusiones y Actas de Cortes (en adelante $D D A C$ ) dará cuenta de cómo, en esta primera intervención, este diputado lanzará una sanción discursiva al despotismo del que han sido objeto los territorios americanos y "sus naturales" durante más de tres siglos:

Apenas queda tiempo ya para despertar del letargo, y para abandonar los errores y preocupaciones hijas del orgullo y vanidad. Sacuda V.M. apresuradamente las envejecidas y odiosas rutinas, y bien penetrado de que nuestras presentes calamidades son el resultado de tan larga época de delitos y prostituciones, no arroje en su seno la antorcha luminosa de la sabiduría, ni se prive del ejercicio de las virtudes. Un pueblo que oprime a otro no puede ser libre. [cursivas del autor] (DDAC, 1810, tomo II, p. 16)

Una denuncia que señala la opresión histórica de España hacia América no debió caer bien en el contexto de la crisis monárquica, pues se configuran en un escenario de sometimiento y rivalidad frente al enemigo francés, teniendo, además, por otro lado, las amenazas autonomistas americanas. No es casual que el diputado se presente como "Inca, indio y americano", reivindicando su linaje y ascendencia, señalando su posición representativa con respecto de los indígenas y manifestando un afán de reivindicación colectiva y nacional sobre todo un continente. No es casual que su discurso se oriente en el sentido de crítica a la opresión, en tanto podía resultar como fórmula de chantaje por parte de América, reconociendo una oportunidad importante para lograr una mayor representación del continente frente a la península; de ahí los vanos intentos, por parte de los peninsulares, por retrasar la discusión.

El día 9 de enero de 1811 se dispuso la continuación de lo planteado por los americanos el 16 de diciembre. Para esta discusión se leyó una propuesta de los americanos, que decía así:

En consecuencia del decreto de 15 de octubre próximo, se declara que la representación nacional de las provincias, ciudades, villas y lugares de la tierra firme de América, sus islas y Filipinas, por lo respectivo a sus naturales y originarios de ambos hemisferios, así españoles como indios, y los hijos de ambas clases, debe ser y será la misma en el orden y forma (aunque respectiva en el número) que tienen hoy y tengan en lo sucesivo las provincias, ciudades, villas y lugares de la península e islas de la España europea entre sus legítimos naturales. (DDAC, 1810, tomo II, pp. 316-317).

De esta propuesta se desprende una lógica representativa encarnada en corporaciones. Lo que se pretende representar no son ciudadanos o individuos (la ciudadanía aún no es discutida) como integrantes de la nación; lo que se quiere representar son los cuerpos que configuran la monarquía, de ahí que se establezcan lógicas representativas territoriales antes que supuestos modernos de representación. Más aún, el diputado Quintana señaló que estaba de acuerdo con la totalidad de esta propuesta, pero que era importante otorgarle algunos añadidos, como, por ejemplo, que se separasen las "clases de habitantes" en el censo que debería hacerse, estableciendo una separación entre

indios, criollos, mestizos y europeos, y cada una de las cuatro será representada por el número de diputados que le quepa, es decir, 
que el indio ha de ser representado por indio, el criollo por criollo, el mestizo por mestizo y el europeo por europeo.

Además, sostenía que las castas (asumidas estas como poblaciones sin vínculos indígenas e hispanos) tendrán derecho a ser representadas, pero que no participarán en la elección de sus representantes, los que serán representados por la "clase de los mestizos" (considerados estos como la mezcla de lo indígena con lo hispano), y, por último, defendía la posibilidad de que la esclavitud sea suprimida y que, en ese camino, los también señalaba que no había forma de establecer la representación americana sin tomar en cuenta su particularidad social. "En aquél hemisferio nos hallamos con una población que excede a la de la madre patria, y con la dificultad de clasificarla" (DDAC, 1810, tomo II, p. 323); el diputado Utges señalaría que

según lo que he oído, algunos señores americanos admiten para esto ciertas castas que otros excluyen. La diferencia que hay entre blancos y pardos, el modo con que se hallan constituidos, y otras diferentes cosas que no tengo presentes, y que solo

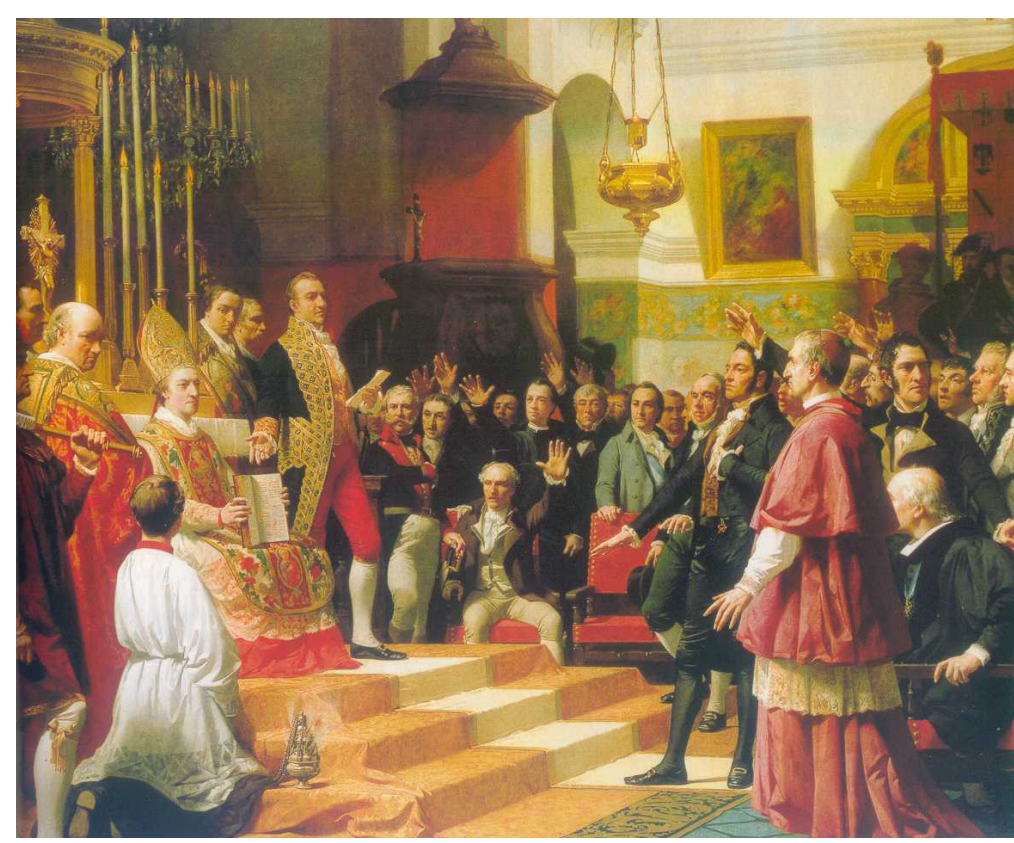

Juramento de las Cortes de Cádiz (1862), de José Casado del Alisal (Congreso de Diputados de Madrid)

esclavos serán representados por un europeo (DDAC, 1810, tomo II, p. 317). Más allá de que estos dos últimos puntos suponían ir mas lejos de lo que el decreto del 15 de octubre disponía, en tanto las poblaciones que tienen origen africano estaban excluidas, lo cierto es que la lógica de representación que proponía el diputado Quintana reposa también sobre lógicas étnicas y corporativas propias del antiguo régimen.

El diputado Argüelles, quien se proclamaba defensor de la igualdad de representación entre peninsulares y americanos, pero cuestionaba que esta discusión se llevara a cabo antes del establecimiento de la Constitución, cito para hacer ver la dificultad que hay para fijar esta representación. (DDAC, 1810, tomo II, p. 325)

Por otro lado, añadía el propio diputado Argüelles, la lógica de representación tiene que ser definida y establecida en la Constitución, "Además, el sistema representativo de la nación es muy moderno, no le han conocido los antiguos" (DDAC, 1811, tomo II, p. 322). Notorio es que parte de la agenda liberal consistió en empezar a destruir los cimientos de las lógicas corporativas y estamentales de la representación. Quizás por este lado se encuentre un argumento más para señalar el por qué de posponer el debate cuando se discuta la propuesta de Constitución. En ella se plasmarían los ideales modernos de la representación y los criterios de la igualdad. Sin embargo, fue imposible postergar este debate, en tanto los americanos se jugaban sus cartas en las circunstancias de crisis de la monarquía. Por eso que el debate se movió en un terreno bastante antagónico como confuso, no solo por lo compleja que era la sociedad del continente americano, sino porque a través de este debate se introducían cuestiones y lógicas de representación del antiguo régimen, como las que hemos señalado líneas arriba.

Las ideas de representación y los conceptos que se tienen de representación entrarán en enfrentamiento discursivo entre lo que se presume como moderno y aquello que representa lo tradicional. Así como los americanos luchan por aumentar su representación, estarán quienes vean en esta la posibilidad de los reclamos de quienes no se sientan representados. El diputado Villanueva llamará la atención de esto, así como los diputados americanos exigen una ampliación de su representación. Así, "Ios estamentos ni todas la ciudades de voto en Cortes que por ley o privilegio asistían antes, hoy ni se quejan" (DDAC, 1810, tomo II, p. 355) y ampliará el diputado Caneja: “¿los estamentos y varias ciudades que se creen igualmente defraudadas de este derecho [...] no reclamaría[n] si viesen que se atiende ahora a las quejas de América?" (DDAC, 1810, tomo II, p. 357). En efecto, existe el temor, ya sea un temor fingido para posponer la discusión o temor real por parte de los liberales, para quienes esta discusión generaría el reclamo de aquellos estamentos en los que antes y, por privilegio, tenían derecho a la representación.

No es de nuestro interés tratar de entender las lógicas políticas de esta pugna entre peninsulares y americanos, sino que, a través de la misma, podemos reconocer lo que se define como representación. Esto es importante porque nos plantea la entrada para entender la lógica y la relación entre representantes y representados, es decir, empezar a dilucidar que no 
solo es importante la representación por la representación, sino más bien la representación por lo que se representa; así y todo, los diputados presentes en las Cortes son depositarios de la soberanía nacional, y tal como se dispuso desde el 24 de setiembre de 1810, los diputados representan a la nación. Aquí es necesario hacer un paréntesis: ¿qué se entiende por nación? Dentro de la multiplicidad de referentes conceptuales sobre la voz nación hay una que destaca por estar vinculada a nuestro interés, como bien señala Fabio Wasserman (2008). La voz nación era empleada para designar a poblaciones que compartían rasgos físicos o culturales como lengua, religión y costumbres. Este término se utilizaba para designar pueblos considerados por su alteridad, ya sean bárbaros, gentiles, paganos, idólatras o simplemente monstruosos. En América asumió un carácter más preciso al utilizarse para hacer referencia a grupos étnicos o castas (p. 853). En este sentido, no es de sorprender que se empezara a cuestionar el reclamo de los americanos en cuanto a que la consideración de lo que se reclamaba era la inclusión de las "naciones" para su representación. De aquí que algunos diputados hayan señalado la posibilidad de la representación por categorías étnicas que también podrían ser consideradas como representaciones "nacionales". Por otro lado, la nación es también vista como "la colección de los habitadores en alguna provincia, país o reino", como referente de territorio y población; por lo tanto, cabría preguntarse, ¿qué es lo que se busca representar cuando se discute la cuestión americana? De esto surge quizás otra razón para entender las dilaciones que pretendieron dar los peninsulares a la cuestión americana. El momento en que ellos consideraban propicio delimitar las formas y qué representar se tenía que discutir durante la presentación de la Constitución. Es en ella en la que se precisarían no solo lo anterior, sino la homogenización de los conceptos en clave moderna; sin embargo, este debate propició visualizar los viejos conceptos y, por lo tanto, resultó que el debate se les fuera de las manos a los liberales españoles.
Mas allá de esto, y gracias al debate, es que se nos permite entrar a las concepciones de las diferentes categorías étnicas. Ramón Feliú sería uno de los primeros en responder todos los cuestionamientos que se presentaron por parte de los peninsulares para no discutir la cuestión americana. Señala el diputado peruano que lo que se esconde detrás de estos obstáculos son los temores a que la representación americana superase en número a la peninsular y él mismo se pregunta: " ¿a qué se debe esa representación mas numerosa?, dicen algunos ¿de qué nos servirán los diputados de la clase de indios?", entonces, según Feliú, el temor no solo está en la mayoría que alcanzarían los americanos, sino en la posibilidad de que la representación recayera sobre los indios; por esto es que el debate girará en torno a las condiciones y capacidades de los indios para asumir la representación con legítimo derecho a partir del decreto del 15 de octubre de 1810, y, por otro lado, abrirá paso para la discusión de las otras realidades étnicas en América, como las castas. Dice Ramón Feliú sobre los indios:

$Y$ hablando de los indios, a quienes conozco por experiencia, digo, que son un pueblo humildísimo, fidelísimo, austero, integérrimo y poseedor de ciertas virtudes sociales, que ya no existen en otra parte de la tierra; pero no un pueblo de luces. Sus representantes no ilustrarán a los de la Península acerca de las grandes máximas de gobierno y de alta política; pero les dirán verdades, los instruirán en hechos que no tienen noticia ni aun idea. (DDAC, 1811, tomo II, p. 351)

La apelación discursiva a los indios será recurrente. No pretendemos señalar aquí el surgimiento de un protoindigenismo en tanto estamos frente a un debate político con intereses de por medio, sin embargo, observamos que dentro de estas pugnas se empiezan a esgrimir concepciones acerca de los indios, como por ejemplo el señalamiento de su "falta de luces" (que será un elemento recurrente en los debates políticos del siglo xIX), pero que el "abatimiento" de estas poblaciones se debe al estado de postración que han tenido en tres siglos de despotismo. El diputado Quintana, quien expresaba el 11 de enero de 1811, "pobrecitos indios", que los ubicaba como "hermanos nuestros" y que "cada lágrima suya es una bala que mata a un guerrero nuestro; que fueron dueños del país, y que nada que no sea suyo les damos con igualarlos en todo a nosotros" (DDAC, 1811, tomo II, p. 363), señala que la idea de igualdad es establecida en términos de redención de las poblaciones naturales y originarias del continente americano a las vejaciones sufridas; es interesante notar el giro del debate situándolo en función de un reclamo étnico. El diputado peruano Morales Duárez hace un señalamiento muy acucioso de la situación de los indios, además de que refuerza la idea de su postración a razón de la dominación y el despotismo establecido sobre ellos, y en donde, asimismo, concluye que los males de esta población son los males del continente, señalando, por ejemplo, que apenas se hizo la primera "numeración" de indios en el Perú, en 1591, se lograban encontrar 8 2550000 y que para 1794 solo se tenía 619 190, y exclamará que esta "asombrosa desolación" de los "miserables indígenas" está relacionada con la "oscuridad y abandono" de los españoles criollos (DDAC, 1810, tomo II, p. 372).

La utilización retórica de los indios por parte de los diputados americanos generó que el debate siguiera un curso étnico racial, pero, por otro lado, también generó reacción frente a la posibilidad de conceder la igualdad a través de la ciudadanía a los indígenas, hubo quienes consideraron reconocer la igualdad de representación, pero, al mismo tiempo, excluir de la misma a los indios...

que aún enclavados en nuestros dominios y habitantes en ellos, no viven sometidos a nuestro gobierno mientras así existan, ora se hayan substraído de nuestro gobierno después de conquistados, ora nunca lo hubiesen sido; pues no puede con verdad decirse ni que sean súbditos de V.M. ni que 
le auxilien ni aún le obedezcan. (DDAC, 1811, tomo Il, p. 420)

La reacción conservadora no se haría esperar; en este mismo sentido, el sacerdote peruano Ostolaza atacaría señalando que la igualdad concedida a los americanos para ser reconocidos como ciudadanos no les da el derecho de igualdad en la representación (DDAC, 1811, tomo III, p. 19). Esto no haría más que avivar aún más el debate.

El 23 de enero de 1811 continuaba el debate y el diputado Quintana volvió a sugerir la lógica de la representación corporativa étnica, señalando, además, "veamos de una vez que todos tenemos alma racional, y que somos hijos de Adán" (DDAC, 1811, tomo III, p. 61). El argumento de la igualdad natural concebida además a través del derecho escolástico, será una herramienta fundamental pero con lógicas diferencias, añadiendo lógicas corporativas de igualdad intraétnica o intraestamental; por esa razón los peninsulares utilizarán el último elemento que les queda disponible para posponer el debate hasta la Constitución: este elemento sería el de las castas. Como señalaría el diputado Argüelles, concedida la igualdad de ciertas clases (en este caso, los indios) esta sería susceptible de resentimientos por parte de las clases excluidas (las castas). España no es América. En la primera no se encuentran esas diferencias notorias a partir de la heterogeneidad de la segunda (DDAC, 1811 , tomo III, p. 68). El argumento del resentimiento de los excluidos seránotorio. El diputado Borrull manifestaría que la propuesta de igualdad entre españoles europeos y españoles americanos (incluidos los indios), "que excluye a las demás castas de los rangos honoríficos de diputados, se valdrían de semejante ocasión los facciosos para atraerles a su partido, y a militar bajo de sus banderas, ofreciéndoles amplísimos privilegios" (DDAC, 1811, tomo III, p. 83). Temores a la sedición y al levantamiento por parte de las castas es lo que aparece en las intervenciones, temores que son graficados por los sucesos ocurridos en la isla de Santo Domingo; las mismas que tendrán respuesta por parte de los americanos. El diputado Guridi y Alcócer manifestará que no debe generar temor la exclusión de las castas a la sedición, en tanto las mismas han sido excluidas desde siempre de la nobleza y "cargos honrosos" y que a razón de eso se han habituado a la exclusión, sostiene que Santo Domingo es un ejemplo del durísimo yugo del gobierno francés y que esos ánimos no han trascendido a Cuba, que tiene igual cantidad de población negra, en donde, sin embargo, el gobierno español ha suavizado su esclavitud en comparación al gobierno francés (DDAC, 1811, tomo III, p. 91).

Las posiciones más radicales se empezaron a manifestar cuando la idea de igualdad a partir de la propuesta americana empezaba a tener aceptación (mas allá del cuándo se tenía que poner en práctica esta igualdad). El diputado Valiente señalaría refiriéndose a las "razas" (castas), que, siendo aproximadamente cinco millones, hay un considerable número de razas subalternas y de "ilegítima extracción", que se distinguen no solo por el color, sino por las costumbres, y por la más o menos capacidad para desarrollar algunos oficios. No existe, según este diputado, uniformidad en ellas, y que las leyes que tienen el encargo de mirar por igual a estas poblaciones, la misma solo está sujeta a la protección. Llama la atención la comparación que empieza a hacer entre los españoles y estos últimos, unos son pocos y los otros son muchos, "y además los aventajan en robustez, y en osadía, con este motivo se les castiga con mucha severidad" (DDAC, 1811, tomo III, p. 75). La idea de las costumbres atribuidas a esta diversidad es interesante; ya para el siglo XVII y con más razón en el siglo XVIII se pueden observar en los espacios urbanos como las castas empiezan a desarrollar complejos procesos de jerarquización. Dicha clasificación no se basaba solo en el color de la piel. Pertenecer a una casta, además, implicaba combinar elementos únicos. Por ello, una casta era identificada de acuerdo a su vestimenta, hábitos de consumo, relaciones sociales, oficios, así como otras características (0’Toole, 2005, pp. 72-74). El mismo diputado valiente, hablando de los indios, dijo:
Siendo esta la porción mas considerable en el número, la originaria de aquel país, y la mas considerada y defendida de las leyes, es tal la pequeñez de su espíritu, su cortedad de ingenio, su propensión al ocio, a la oscuridad y al retiro [...]. Si se permite que los de otras clases, incluso la de los españoles, se establezcan en sus pueblos, se disgustan, se huyen y se acaban [...] En este estado de incapacidad y minoría legal sería absurdo habilitarlos para las importantes funciones de intervenir en las Cortes". (DDAC, 1811, tomo III, p. 75)

Incapacidad y minoría de edad; será notorio que esta idea estará presente a Io largo del siglo XIX, cuando se discuta la ciudadanía indígena, la minoría de edad como garante de incapacidad y de voluntad propia; además, como sostiene el mismo diputado Valiente, "la ley los estima en la capacidad de aun menos de siete años" y que, además, no hay ley que no proteja a los indios como se hace en las actuales circunstancias; "no hay español que se atreva a molestarlo sin exponerse casi inevitablemente a su ruina, porque todas las autoridades se conspiran contra él"; la exclusión de ellos se garantiza en su minoría de edad y en que aún son objeto de protección por parte de las autoridades. No habrá quienes rechacen estas connotaciones; el diputado Lisperguer, quien, señalando que, además de ser considerados los indios como menores, se les quiera constituir como "poco menos que bestias"; la "rudeza" que experimentan estos indios se debe a la opresión y tiranía con que son tratados; "nada hace al hombre más estúpido y pacato, que la opresión y la injusticia; nada hace triunfar mas al despotismo, como el mantener los pueblos en la ignorancia" (DDAC, 1811, tomo III, p. 87), este mismo diputado no se detendrá en afirmar ciertas consideraciones de índole corporativa y étnica. "Ya llegó el tiempo de ser tratados estos infelices como hombres, y de que sean útiles para sí y para su patria". Patria vinculada a la idea nación de indios; interesante además notar, como lo harán otros diputados, que las objeciones puestas sobre los indios tendrán respuesta inmediata; 
además de la "minoría de edad" de los indios, se sumarán su ignorancia, su poco conocimiento del castellano, por ser desaseados y sucios y por el número grande que representan. El diputado Guridi y Alcócer sostendrá que la minoría de edad es reconocida por las leyes de indias pero esta es "para escudarlos contra las vejaciones a que los expone su miseria; pero son menores por privilegio..."; siguiendo en este tenor, manifestará que las leyes no los restringen para obtener empleos, y prueba de ello es que la dignidad episcopal requiere de treinta años, y que esto no ha sido obstáculo para que algunos alcancen esa dignidad; sobre la ignorancia "Es verdad que el común de ellos no tiene la ilustración de que son capaces, exigiéndolo así su infeliz situación y crianza, con la que hasta Newton y Leibnitz no hubieran pasado de ser unos rudos."; sobre su desencuentro con el castellano recordará este diputado que lo mismo debería decirse de los vizcaínos "porque los mas no entienden mas que sino el vascuence" (DDAC, 1811, tomo III, pp. 93-94).

Más enérgico fue el diputado Feliú al proponer un desconocimiento real por parte de los peninsulares y de los que se oponen a la igualdad respecto a los "indios antiguos" y a los de hoy, en una disertación que bien pudiera parecer un panegírico, pues las alabanzas a las bondades de los indios antiguos son elocuentes:

Los que llaman brutales y tiranos a los antiguos indios, ¿saben qué era el llactacamyu del Perú? Era el ministro público destinado a favorecer y amparar en todo a las viudas y los huérfanos... Véase aquí a los indios..., que después de su dios a nada atendían más que a los desvalidos; ¿saben de los famosísimos obeliscos y estatuas tiahuanacu, de los mausoleos de Chachapoyas, de los edificios de Cuzco y Quito....¿han leído por ventura sus idilios, sus elegías y sus odas?, ¿han sentido alguna vez la suavidad, ternura y dulcísima melancolía de sus yaravíes?
Las alusiones a las bondades de los antiguos contrastan con la situación de los actuales, pero estas mismas condiciones actuales están en relación con lo que muchos otros diputados ya habían señalado: el grado de arbitrariedad con que fueron tratados en los últimos tres siglos. Más aún, fustigó contra las corrientes naturalistas que utilizaron los diputados peninsulares para cuestionar la capacidad de los indígenas. En efecto, algunos diputados españoles utilizaron el término indio como "tirano y brutal", citando a Humboldt, quien para el diputado peruano no estaba en condiciones ni tenía autoridad para opinar sobre las cuestiones de América: "se paseó bastante (hablando de Humboldt y su paso por Lima), e hizo en un hospital dos 0 tres experimentos galvánicos, con 10 cual se creyó autorizado para hablar ex catedra de todo lo relativo a América" (DDAC, 1811, tomo III, pp. 160-166).

Esto último nos permite encontrar, y a través de todo este debate, es que se empieza a construir una imagen diferenciada del indio. Como advertimos líneas arriba no estamos sugiriendo la idea del surgimiento de un protoindigenismo, pero sí nos parece importante señalar que es este contexto en que se genera un espacio diferente a lo que venía sucediendo, por ejemplo, en el Perú, a fines del siglo XVIII. En este periodo las ideas que provenían de Europa tuvieron difusión en el continente americano. En 1778, el escocés William Robertson planteó en términos históricos, las comparaciones geográficas y climáticas, postulando la inferioridad del indígena americano. Frente a estas teorías, llama la atención el relativo silencio de los intelectuales y pensadores criollos. "Las ideas europeas representaron un reto que los intelectuales criollos no pudieron enfrentar satisfactoriamente" (Walker, 1996, p. 92). Esta limitación de los intelectuales americanos es representada por Pablo Macera así:

Frente al buen salvaje y al indio inmaduro, invenciones opuestas y a la vez complementarias de la literatura europea, los criollos y peninsulares del Perú no supieron construir una imagen propia, razonable y sencilla del indio; salvo algunas excepciones - Loredo, Eyzaguirre, Mata Linares-, el Perú que pretendieron reformar siguió siendo 'su' Perú, el Perú blanco y occidental nacido con la conquista española del siglo xvı. (Macera, 1977, pp. 310-316).

Estas afirmaciones aluden al papel que jugó el Mercurio Peruano en su intento por responder las ideas europeas, los intelectuales y académicos peruanos trataron de refutar estas ideas europeas ensayando una especie de nacionalismo criollo científico, sin embargo no se preocuparon en señalar alguna relación con la población indígena, es una respuesta anti europea más que una preocupación real por estudiar las condiciones de los indígenas. Sin embargo, esta situación cambiaría con las Cortes, que sin proponérselo (los diputados americanos) terminaron respondiendo los señalamientos europeos con respecto a la población indígena.

Así, tenemos que este contexto inaugurado por las circunstancias militares y políticas de la península dio origen a una discusión sobre las poblaciones y sus características étnicas, particularmente en el caso americano, y que, por otro lado, iniciará el camino de discusión sobre la inclusión indígena a la ciudadanía. En 1812, proclamada y juramentada la Constitución, se reconocerá esta inclusión y, por lo tanto, su participación en las elecciones que se inaugurarán en este contexto. Si bien la constitución tendrá corta duración (1812-1814), la misma es un ejemplo valioso para entender cómo fueron imaginadas y pensadas, desde la modernidad política, las poblaciones indígenas. No es solo un contexto particular. El mismo escenario lo encontraremos a lo largo del siglo XIX, donde la discusión de la ciudadanía indígena será un referente importante para entender los proyectos de nación que se vislumbrarán en décadas posteriores. 


\section{Fuentes documentales}

Cortes Generales de Cádiz (1810-1813). Diario de Discusiones y Actas de Cortes (tomos II y III). Cádiz: Imprenta Real.

\section{Bibliografía}

Anna, T. (2003). La caída del gobierno español en el Perú. El dilema de la independencia. Lima: Instituto de Estudios Peruanos.

BASADRE, J. (1980). Elecciones y centralismo. Apuntes para un esquema histórico. Lima: Universidad del Pacífico.

Berruezo, M. (1986). La participación americana en las Cortes de Cádiz (1810-1814). Madrid: Centro de Estudios Constitucionales.

Castillo, F., Figallo, L., y Serrera, R. (1994). Las Cortes de Cádiz y la imagen de América. La visión etnográfica y geográfica del Nuevo Mundo. Cádiz: Universidad de Cádiz.

Chust, M. (1999). La cuestión nacional americana en las Cortes de Cádiz. Valencia: Fundación Instituto Historia Social y Universidad Nacional Autónoma de México.

Chiaramonti, G. (2005). Ciudadanía y representación en el Perú (1808-1860). Los itinerarios de la soberanía. Lima: Universidad Nacional Mayor de San Marcos y Oficina Nacional de Procesos Electorales.

Demélas-Bohy, M. (2003). La invención política. Bolivia, Ecuador y Perú en el siglo xix. Lima: Instituto Francés de Estudios Andinos e Instituto de Estudios Peruanos.

Fisher, J. (1979). Royalism, Regionalism, and Rebellion in Colonial Perú, 1808-1815. Hispanic American Historical Review, 59(2), 232-257.

GuerRA, F.-X. (1992). Modernidad e independencias. Ensayos sobre las revoluciones hispánicas. México, D. F.: Mapfre y Fondo de Cultura Económica.

Hamnett, B. (1978). Revolución y contrarrevolución en México y el Perú. Liberalismo, realeza y separatismo, 1800-1824. México, D. F.: Fondo de Cultura Económica.

Hunefeldt, C. (1978). Los indios y la Constitución de 1812. Allpanchis Phuturinqa, (11-12), 33-57.

Macera, P. (1977). Trabajos de Historia (cuatro tomos). Lima: Instituto Nacional de Cultura.

NúÑEZ, F. (2005). La participación electoral indígena bajo la Constitución de Cádiz (1812-1814). En C. Aljovín de Losada y S. López (eds.), Historia de las elecciones en el Perú. Estudios sobre el gobierno representativo (pp. 361-394). Lima: IEP.

NúñEZ, F. (2007). El concepto de vecino/ciudadano en Perú (1750-1850). Araucaria. Revista Iberoamericana de Filosofía, Política y Humanidades, (17), 235-253.

O’Phelan, S. (2002). Ciudadanía y etnicidad en las Cortes de Cádiz. Elecciones, (1), 165-185.

Paniagua, V. (2003). Los orígenes del gobierno representativo en el Perú. Las elecciones (1809-1826). Lima: Fondo de Cultura Económica y Pontificia Universidad Católica del Perú.

Peralta, V. (2002). En defensa de la autoridad. Política y cultura bajo el gobierno del virrey Abascal. Perú, 1806-1816. Madrid: Consejo Superior de Investigaciones Científicas. 
Rieu-Mıllan, M. (1990). Los diputados americanos en las Cortes de Cádiz. Madrid: CSIC.

Rodríguez, J. (2006). La revolución política durante la época de la independencia. El reino de Quito, 1808-1822. Quito: Corporación Editora Nacional.

Sala VILA, N. (1993). La Constitución de Cádiz y su impacto en el gobierno de las comunidades indígenas en el Virreinato del Perú. Boletín Americanista, (42-43), 51-71.

WaLKER, Ch. (1996). Entre la retórica y la insurgencia: Las ideas y los movimientos sociales en los Andes. Siglo XVIII. Cusco: Centro de Estudios Regionales Andinos Bartolomé de Las Casas.

Wasserman, F. (2008). El concepto de nación y las transformaciones del orden político en Iberoamérica (1750-1850). Jahrbuch für Geschichte Lateinamerikas, (45), 197-220. 